\title{
Estrategias instruccionales utilizadas por los docentes del curso básico de formación de los oficiales de seguridad ciudadana
}

\author{
Instructional strategies used by the teachers of the basic course of \\ training of citizen security officers
}

\author{
- JORGE GUERRERO \\ jorgeguerreroccs@gmail.com \\ Código ORCID: 0000-0002-2785-3981
}

Academia de la Policía Municipal de Sucre, Miranda, Venezuela

Artículo recibido en abril 2020 / Arbitrado en mayo 2020 / Publicado en julio 2020

\begin{abstract}
Resumen La presente investigación se planteó diagnosticar cuáles estrategias instruccionales utilizan los docentes que administran la unidad curricular "Habilidades de comunicación oral y escrita", como parte del curso básico de formación de los oficiales de seguridad ciudadana de la Academia de la Policía Municipal de Sucre, estado Miranda. El enfoque asumido fue el cuantitativo y el diseño de campo de carácter descriptivo. Los instrumentos fueron un cuestionario y una lista de cotejo La muestra estuvo conformada por los seis docentes encargados de administrar dicha unidad curricular. Los resultados arrojaron que los docentes omiten la planeación, ejecución y evaluación de una estrategia instruccional, porque desconocen la forma cómo se organizan y cómo se llevan a cabo las situaciones de enseñanza para promover aprendizajes. De allí que este diagnóstico permitió proponer el diseño de estrategias instruccionales para que los docentes aborden de manera efectiva los procesos de enseñanza y de aprendizaje
\end{abstract}

Palabras clave: Andragogía; estrategias instruccionales; formación policial; comunicación oral y escrita, procesos de enseñanza y aprendizaje

\begin{abstract}
The present investigation set out to diagnose which instructional strategies are used by the teachers who administer the curricular unit "Oral and written communication skills", as part of the basic training course for citizen security officers of the Municipal Police Academy of Sucre, state Miranda. The approach taken was quantitative and descriptive field design. The instruments were a questionnaire and a checklist. The sample was made up of the six teachers in charge of administering said curricular unit. The results showed that teachers omit the planning, execution and evaluation of an instructional strategy, because they do not know the way in which teaching situations are organized and how they are carried out to promote learning. Hence, this diagnosis made it possible to propose the design of instructional strategies for teachers to effectively address teaching and learning processes.
\end{abstract}

Keywords: $\quad$ Andragogy; instructional strategies; police training; oral and written communication; teaching and learning processes 


\section{INTRODUCCIÓN}

En la actualidad es pública y notoria la crisis que vive la sociedad venezolana relacionada con problemas de seguridad ciudadana, exacerbada por un elevado índice de delitos que se cometen a diario y que son conocidos por la población a través de las cifras que comúnmente se transmiten por los medios de comunicación social e incluso a través de las redes sociales. En este contexto, los ciudadanos claman por las instituciones policiales, como organismos con competencia en la prevención y represión de las actividades delictivas, un accionar expedito y apegado a las leyes a fin de disminuir este problema.

El Ministerio del Interior y Justicia (MIJ) a través de la resolución $N^{\circ}$ 124, del 10 de abril de 2006, instala la Comisión Nacional para la Reforma Policial (CONAREPOL), creada por el Ejecutivo Nacional, con el objeto de diagnosticar la situación en ese momento de los cuerpos policiales con el fin de sentar las bases para construir un modelo policial que favorezca la efectividad en este servicio.

El diagnóstico efectuado por esta Comisión de manera pública y con la participación ciudadana a través de diferentes mecanismos, tales como asambleas de ciudadanos, encuestas, tanto personales, como a través del portal web de la comisión, llamó la atención sobre temas relacionados con la formación profesional y la carrera policial. Se inició así la discusión en cuanto a los cambios que debían impulsarse relacionados con el currículo académico, orientado por supuesto, a la gestión y eficiencia de los cuerpos policiales, con el fin de lograr altos niveles de gestión y eficiencia. En este sentido, la CONAREPOL en su informe de Recomendaciones Generales (2007) en su numeral 20 exhortó a:
Adelantar el diseño de planes, programas y curricula de formación básica y continua, en tanto conjunto orgánico, integrado, con políticas y servicios que garanticen la unidad del proceso de formación y el desarrollo profesional permanente, a lo largo de la carrera policial para todos los funcionarios del país y según las funciones y los niveles de intervención le correspondan. (p. 19)

Esta recomendación quedó inserta dentro de los múltiples encargos orientados a conformar el Nuevo Modelo Policial (NMP), propuesto como resultado de esta consulta popular, la cual fue refrendada a través de Ley Habilitante, en el Decreto con Rango Valor y Fuerza de Ley Orgánica del Servicio de Policía y del Cuerpo de Policía Nacional, (L.O.S.P.C.P.N.) en el año 2008 y en la cual se establece en su artículo 58 lo siguiente:

Las funcionarias y funcionarios policiales serán formados en la institución académica nacional, con un currículum común básico y con diversificación según las disciplinas y áreas especializadas del servicio. El Órgano Rector en conjunto con el Ministerio del Poder Popular con competencia en materia de Educación Superior determinará el diseño curricular, las políticas y acciones que garanticen la unidad del proceso de formación y el desarrollo profesional permanente, que debe aplicar la institución académica responsable del sistema único de formación policial. (p. 23) 
Dando cumplimiento a lo señalado, el Órgano Rector, representado actualmente por el Ministerio del Poder Popular para las Relaciones Interiores, Justicia y Paz (MPPRIJP), en conjunto con el Ministerio del Poder Popular con competencia en materia de Educación Superior, formalizaron en el año 2009 la creación de la Universidad Nacional Experimental de la Seguridad (UNES), como la institución universitaria especializada en la profesionalización y el desarrollo integral de los funcionarios de la seguridad ciudadana en el país y que actualmente planifica, diseña y ejecuta la formación inicial de los funcionarios de la Policía Nacional Bolivariana, a través de su Programa Nacional de Formación, además de impulsar la profesionalización policial a través de las carreras de Técnico Superior Universitario (T.S.U.) y Licenciatura en Servicio Policial, para ser cursadas por todos los funcionarios de las policías, tanto Nacionales, como Estadales y Municipales.

Actualmente continúa en proceso esta reforma policial, la cual incluye las modificaciones pertinentes en la formación y capacitación de los funcionarios policiales. En este sentido, existe una especial preocupación por los diferentes factores que influyen en la formación y desarrollo de las competencias que deben tener los futuros oficiales de policía una vez egresados de las instituciones encargadas de su formación inicial.

En este contexto, las policías estatales y municipales que tienen en su estructura direcciones de educación, capacitación y/o formación, incluyendo academias de formación de funcionarios policiales, deben apegarse a los lineamientos establecidos por la UNES, la cual acredita los procesos de formación policial.

En la academia del Instituto Autónomo de Policía Municipal de Sucre del Municipio Sucre del Estado Bolivariano de Miranda (I.A.P.M.S.) se dicta el curso básico para oficiales de seguridad ciudadana, con el cual se educan y forman a los oficiales de la Policía Municipal de Sucre (P.M.S.). Dicho curso es estandarizado para todas las instituciones y academias de formación de funcionarios policiales en Venezuela y que, de acuerdo con la malla curricular emanada de la UNES, tiene una duración de trece meses y está dividido en: (a) un trayecto inicial de diez semanas, (b) seguido por tres trimestres, con una duración de doce semanas cada uno, y (c) culminando con un período de pasantías, el cual comprende seis semanas de actividades.

En el trayecto inicial, se dictan seis unidades curriculares, a saber: Unes Plan de Desarrollo Nacional, Historia de la Seguridad, Aprender a Aprender, Orden y Desplazamiento, Matemática Básica e Introducción a las Tecnologías de la Información. En los siguientes tres trimestres, la malla curricular está conformada por las siguientes unidades curriculares: Investigación e Innovación, Marco legal de la función policial, Vigilancia y Patrullaje, Uso progresivo y diferenciado de la fuerza, Educación física, deportes y recreación, Habilidades de comunicación oral y escrita, Técnicas básicas de operaciones policiales, Actas y Documentos Policiales y el Seminario de Formación Sociocrítica (en el cual se desarrollan los aspectos relacionados a la atención a la víctima, 
sociedad y democracia socialista y derechos humanos). El curso de formación policial culmina con el desarrollo de las pasantías y actividades de acercamiento comunitario, en el cual los aspirantes a oficiales de policía acompañan a los integrantes de las diferentes oficinas y unidades operativas del IAPMS, en su labor diaria de prevención del delito y ejecución de diversos programas comunitarios. Una vez culminado el curso, los estudiantes egresan como Oficiales de Seguridad Ciudadana, tienen la posibilidad de continuar sus estudios universitarios en la UNES.

Los docentes que dictan las unidades curriculares antes presentadas son, en su mayoría, funcionarios policiales, fiscales, jueces, sociólogos, instructores, trabajadores sociales, abogados, administradores, criminalistas, entre otros; con amplia experiencia en la disciplina que imparten y que han desarrollado su carrera policial en diferentes áreas o en el ejercicio de funciones públicas relacionadas con la seguridad ciudadana; pero en su mayoría sin formación pedagógica por lo que carecen de herramientas didácticas, para llevar a feliz término la consecución de los objetivos que se buscan en el proceso educativo de formación inicial de los futuros funcionarios policiales.

La escasa formación pedagógica y el desconocimiento de estrategias instruccionales que presenta la generalidad de los docentes de esta academia redundan en fallas en la instrucción $y$, por ende, en el logro de los objetivos de las unidades curriculares.

En la experiencia del autor de esta investigación, quien forma parte de esta institución policial, entre las fallas más relevantes que se observan en los estudiantes egresados de los cursos de formación de funcionarios policiales son las debilidades que presentan en cuanto a la redacción de los documentos que deben elaborar rutinariamente en el ejercicio de sus funciones; además de las pocas habilidades que demuestran para comunicarse oralmente, tanto con sus compañeros de trabajo, como con las personas con las que interactúan diariamente en su labor policial.

Esta situación se presenta aun cuando en la malla curricular de la UNES que se administra en la Academia de la Policía Municipal de Sucre se facilita la unidad curricular denominada: "Habilidades de comunicación oral y escrita", en la cual se imparten contenidos orientados a desarrollar habilidades para la comprensión de la lectura, la redacción, la oratoria y la comunicación interpersonal. Sin embargo, son notorias las deficiencias en estos aspectos con las que egresan de la Academia los futuros oficiales de policía. Por consiguiente, el bajo rendimiento académico en esta unidad curricular es común en la mayoría de los participantes, lo que indudablemente afecta su futuro desempeño profesional.

Esta situación es motivo de preocupación por parte de las autoridades directivas del IAPMS, debido a que los discentes no dominan las capacidades a que hace referencia el programa de formación inicial en relación con esta unidad curricular.

La carencia del logro de competencias en los educandos en proceso de formación puede derivar en malas actuaciones policiales, lo que implica un riesgo tanto para el oficial de policía, como para los miembros de la sociedad donde desempeña su función; es decir, al no efectuar los procedimientos policiales de acuerdo con lo 
establecido en los lineamientos pudiera estar incumpliendo normas legales de índole penal que ponen en riesgo su carrera policial y el desempeño institucional. Esto se observa con mayor énfasis en la redacción de las actas e informes policiales que deben elaborarse al momento de efectuar un procedimiento policial; documento que debe ser redactado exclusivamente por el funcionario actuante. Dicho documento es el punto de partida para iniciar los expedientes penales que elaboran tanto el Ministerio Publico, como los Tribunales de la República.

De igual manera, al ser la función policial un senvicio dirigido directamente a las comunidades es importante que los profesionales de esta área desarrollen capacidades adecuadas de comunicación interpersonal que les permitan dirigirse adecuadamente a cualquier persona.

Es muy probable que los funcionarios públicos en calidad de docentes que administran esta unidad curricular estén carentes de la preparación pedagógica idónea para impartir los conocimientos y habilidades necesarias; por tanto, no utilizan las estrategias más adecuadas para cada contenido, limitándose a la transmisión oral de la teoría.

Pareciera que lo anterior redunda en la ausencia de estrategias instruccionales, por lo que es posible presumir que no se estén promoviendo las estrategias de aprendizaje adecuadas. Lo anterior puede influir en el rendimiento académico de los estudiantes y en consecuencia deficiencias en la formación evidenciadas en su desempeño como funcionarios policiales y específicamente en los frecuentes errores en que estos incurren en la redacción de diversos documentos que se elaboran en el desempeño de la función policial, tales como las actas policiales, los informes de procedimientos, novedades, etc.; por otro lado, se presentan constantes denuncias en el I.A.P.M.S., de los ciudadanos por irrespeto o por no dar la información necesaria de forma correcta, lo que origina sanciones disciplinarias para estos agentes.

Por lo antes expuesto, se planteó como objetivo general diagnosticar las estrategias instruccionales que emplean los docentes que administran la unidad curricular Habilidades de comunicación oral y escrita en la Academia de la Policía Municipal de Sucre (Guerrero, 2018).

\section{El nuevo modelo policial}

Las estrategias instruccionales que pueden aplicar los docentes en el curso de formación inicial para funcionarios policiales $y$ específicamente en la unidad curricular "Habilidades para la comunicación oral y escrita" deben ser implementadas bajo los preceptos establecidos en el Nuevo Modelo Policial, el cual fue descrito por primera vez en las recomendaciones de la Comisión Nacional para la Reforma Policial (2007), documento suscrito por el Ministerio de Interior y Justicia, actualmente Ministerio del Poder Popular para Interior, Justicia y Paz.

Este documento, en su capítulo IV, establece un resumen de las recomendaciones para la implementación del nuevo modelo policial, las cuales se transcriben a continuación:(a) elaborar la ley de bases y demás normativa que regula el sistema integrado de policía y demás leyes vinculadas a los cuerpos policiales según lo previsto en el 
Modelo propuesto..., (b) difundir, exigir y supervisar el cumplimiento del código de conducta policial, (c) la policía debe ser entrenada en la protección de los derechos humanos..., (d) implementar medidas para evitar que la policía suspenda la prestación del servicio por ningún motivo, (e) adoptar criterios de evaluación de desempeño policial...,(f) los distintos cuerpos de policía deben preparar un plan anual de gestión, (g) elaborar los protocolos de intervención policial..., (h) diseñar una política sobre uso de fuerza física..., (i) desarrollar manuales y protocolos para la aplicación de escalas progresivas en el uso de la fuerza física en función de la resistencia del ciudadano, (j) adoptar un plan para la policía de dotación y mantenimiento de la capacidad operativa..., (k) consolidar la base de datos nacional sobre la policía venezolana en el ámbito nacional, regional y municipal... (I) ejecutar, a la brevedad posible, un inventario digitalizado de todas las armas orgánicas, particulares y retenidas, así como un registro balístico, $(\mathrm{m})$ implementar un programa de acreditación de buenas prácticas policiales..., y (n) regular la reasignación en una actividad compatible con su formación y las necesidades del servicio de aquellos funcionarios presuntamente incursos en delitos y faltas graves mientas se resuelve definitivamente su situación.

De lo antes expuesto, derivan los lineamientos estratégicos que deben regir la conformación del nuevo modelo policial y en el cual deben desenvolverse los futuros egresados de los cursos de formación inicial de funcionarios policiales.

En relación con la educación dentro del Nuevo Modelo Policial, el Consejo General de
Policía- Comisión Nacional para la Reforma Policial (2010), señala:

En el nuevo modelo se plantea el diseño de un sistema homogéneo y estandarizado para la formación básica y continua para todos los cuerpos policiales. Debe ser un conjunto orgánico, integrado, con políticas y servicios que garanticen la unidad del proceso de formación y el desarrollo profesional permanente, a lo largo de la Carrera Policial para todos los funcionarios y funcionarias del país. (p. 11)

De allí la importancia de considerar los lineamientos de la UNES, relacionados con la administración de los contenidos curriculares en la formación de oficiales de policía, ya que se plantea en el Nuevo Modelo Policial una formación y educación estandarizada para todos los cuerpos policiales del país.

\section{Estrategias instruccionales}

La estrategia instruccional consiste en la planificación y ejecución de la forma como se organizan y llevan a cabo las situaciones de enseñanza con el fin de promover determinados aprendizajes. De acuerdo con Smith y Ragan (1999) "una estrategia instruccional consiste en la organización secuencial por parte del docente, del contenido a aprender, la selección de los medios instruccionales idóneos para presentar ese contenido y la organización de los estudiantes para ese propósito" (p. 3). En tal sentido, se entiende que el docente tiene la posibilidad de planificar previamente la secuencia de los nuevos contenidos, eligiendo aquellos medios 
instruccionales ideales para impartirlos, tomando en cuenta el grupo de estudiantes a fin de organizarlos adecuadamente para el momento instruccional.

La estrategia instruccional es elaborada por el docente con la finalidad de promover el aprendizaje en los estudiantes; de acuerdo al autor, las estrategias se centran en la organización secuencial del contenido a presentar, la distribución del contenido tomando en cuenta los medios a utilizarse incluyendo la forma de organizar a los alumnos y la gerencia para obtener los recursos con la finalidad de que estos dos aspectos se presenten de acuerdo a la planificación planteada.

Por su parte, Szczurek (1989) plantea que la estrategia instruccional "es un conjunto de acciones deliberadas y arreglos organizacionales para llevar a cabo la situación de enseñanza-aprendizaje" (p.15). De igual manera, manifiesta el autor que el diseño de estrategias instruccionales involucra el uso de técnicas o métodos instruccionales específicos, la planificación y ejecución de actividades, la organización de grupos, el control de la secuencia instruccional y la organización adecuada del tiempo y del medio ambiente.

Es imprescindible que se planifique adecuadamente los contenidos que se busca aprendan los futuros funcionarios policiales según los lineamientos de formación inicial planteados en la malla curricular de la UNES, estableciendo previamente cuáles serán las actividades y las técnicas 0 métodos instruccionales propicios, ubicándolas en una secuencia instruccional específica, teniendo control del tiempo y el ambiente, con el fin de lograr los objetivos que plantea la unidad curricular.
En relación con los términos método y estrategia, Szczurek (1989) manifiesta que "Aunque método y técnica se refieren ambos a procedimientos, los métodos son procedimientos más generales aplicables por lo común a diversas áreas del conocimiento, mientras que las técnicas son procedimientos regulares y funcionales más específicos, generalmente propios de ciertas disciplinas" ( $p$. 15).

En el caso de la estrategia instruccional desarrollada en la presente investigación, está referida a la organización de los objetivos y contenidos planteados en la unidad curricular Habilidades de comunicación oral y escrita del curso de formación inicial de oficiales de policía. Estas secuencias pueden estar controladas por el docente directa o indirectamente o por el estudiante dependiendo de la técnica a aplicar.

De igual manera, para Alfonzo (2003) "la estrategia instruccional de organización del contenido es un acto comunicativo y como tal debe tener la estructura de inicio, desarrollo y cierre para tener sentido completo y cumplir su cometido comunicacional" (p. 5).

Es por ello que independientemente del tipo de secuencia con la que se planifique la instrucción, deben considerarse los momentos instruccionales de inicio, desarrollo y cierre, que permitan al estudiante, como lo plantean Smith y Ragan (1999), centrar su atención, percibir selectivamente la nueva información y almacenarla en su memoria a corto plazo, estableciendo relaciones entre la nueva información y sus conocimientos previos, logrando almacenar este nuevo conocimiento en su memoria a largo plazo. 
Estos momentos instruccionales implican eventos instruccionales característicos los cuales se detallan a continuación.

EI inicio. Prepara al estudiante para la instrucción, en él se activa la atención y se promueve la motivación y el interés. De igual forma en su ejecución se presentan los eventos instruccionales que buscan: (a) activar la atención, (b) establecer el propósito, (c) incrementar el interés y la motivación y (d) presentar la visión preliminar de la lección.

El desarrollo. El docente presenta los nuevos contenidos y se desarrollan las actividades orientadas a procesar la nueva información incluyendo de ser necesaria la práctica con el fin de que sea manejada con facilidad por los estudiantes. Así se presentan los siguientes eventos instruccionales: (a) recordar conocimientos previos relevantes, (b) procesar la nueva información y sus ejemplos, (c) focalizar la atención, (d) uso de estrategias de aprendizaje y (e) practicar.

El cierre. Se revisa si se lograron los objetivos de aprendizaje además de ser propicio para promover nuevos aprendizajes y establecer enlaces con diversos contenidos. Dentro de la perspectiva de los eventos instruccionales presentada por Alfonso (ob. cit.) se presentan: (a) revisar y resumir la lección, (b) transferir el aprendizaje, (c) remotivar y cerrar y (d) proponer enlaces.

Por otra parte, Szczurek (1989) propone una serie de componentes fundamentales del proceso de instrucción identificados, con el fin de equipararlos para interrelacionarlos $y$ orientar el estudio, el diseño, el desarrollo y la evaluación de la instrucción, siendo estos los siguientes: los elementos directrices, los estudiantes, el docente, los medios y otros recursos, la evaluación y la estrategia.
Adicionalmente, están otros elementos que se deben considerar. Son estos: técnicas instruccionales, características del estudiante, características del docente, las actividades, la organización de la secuencia, la organización de los grupos, la organización del tiempo, la organización del ambiente.

\section{Habilidades de comunicación oral y escrita}

La unidad curricular Habilidades de comunicación oral y escrita forma parte del Programa Nacional de Formación (PNF) de los oficiales de seguridad ciudadana de la Policía Nacional, las policías estadales y las policías municipales de Venezuela. Está orientada a brindar a los estudiantes las herramientas teórico-prácticas que les permitan fortalecer sus habilidades de comunicación y de reflexión orientado al desarrollo de la carrera profesional los futuros servidores públicos en el área de la seguridad ciudadana.

En ella se busca una comprensión amplia de lo que es el proceso de comunicación, conociendo los diversos tipos de comunicación que pueden aplicar las personas y la importancia de la comunicación para los seres humanos en su compartir en sociedad. Además, se desarrollan tres grandes temas: la comunicación, el lenguaje escrito y el lenguaje oral.

\section{MÉTODO}

La metodología empleada en el presente estudio se rigió por el paradigma cuantitativo.

En cuanto al referido paradigma, Monje (2011) señala que en la investigación 
cuantitativa el investigador debe valerse exclusivamente de la observación directa, de la comprobación y la experiencia. De allí que el presente estudio es cuantitativo porque los datos recolectados en la academia de la Policía Municipal de Sucre fueron tabulados con la finalidad de verificar los planteamientos efectuados en el capítulo I de la presente investigación.

En cuanto al diseño fue una investigación de campo, de carácter descriptivo. Según Farci y Ruíz (2007) la investigación de campo tiene como característica fundamental "que el investigador se pone en contacto con la realidad de la situación, tomado la información directamente de ella" (p. 25); por lo que este tipo de investigación permite no solo observar, sino recolectar los datos de la realidad objeto de estudio, para posteriormente analizar e interpretar los resultados de esas indagaciones. Para ello fue preciso analizar la realidad directamente en el ambiente donde ocurre, específicamente en la sede de la Academia de la Policía Municipal de Sucre.

El nivel del presente proyecto fue descriptivo. Tamayo (2004) señala que la investigación descriptiva "comprende la descripción, registro, análisis e interpretación de la naturaleza actual y la composición o proceso de los fenómenos" (p. 46).

En el presente estudio los datos recabados corresponden al diagnóstico de las estrategias instruccionales que emplean los docentes que administran la unidad curricular Habilidades de comunicación escrita en la Academia de la Policía Municipal de Sucre en la formación inicial de Oficiales de Seguridad Ciudadana.

En cuanto a la población Márquez (2006) la define como "El grupo al cual el investigador trata de aplicar las generalizaciones obtenidas e intenta formar afirmaciones que sean valederas para ese conglomerado" (p. 116). Para efectos de esta investigación, la población la constituyen los seis docentes que administran la unidad curricular "Habilidades de comunicación oral y escrita" del curso de formación inicial de oficiales de Seguridad Ciudadana de la Academia del IAPMS.

Las técnicas utilizadas en esta investigación fueron la encuesta y la observación directa.

Arias (2006) define la encuesta como "una técnica que pretende obtener información que suministra un grupo o muestra de sujetos acerca de sí mismos, o en relación con un tema particular" (p. 72).

Tamayo y Tamayo (1998) señalan que la observación directa "es aquella en la cual el investigador puede observar y recoger datos mediante su propia observación." (p. 122). La observación puede adoptar diferentes modalidades: según el lugar donde se realice; atendiendo al papel o modo de participación del observador y según los medios utilizados.

En esta investigación se adoptó la modalidad de observación directa ya que los datos se recogieron directamente en el escenario de la investigación, con participación directa del investigador y estableciendo de antemano qué aspectos se iban a estudiar; es decir, se observó por un período determinado a los docentes durante la jornada diaria y así poder identificar las estrategias didácticas utilizadas por cada uno de ellos.

Los instrumentos aplicados fueron un cuestionario y una lista de cotejo. El cuestionario quedó estructurado por 20 ítems divididos en dos partes. La primera parte consta de 17 ítems para ser respondidos con 
una escala de frecuencia (siempre, casi siempre, ocasionalmente, casi nunca y nunca). La segunda parte contiene tres ítems para marcar con una equis $(X)$ las opciones que se correspondan con los elementos que emplea el docente encuestado durante sus clases. La lista de cotejo es un instrumento que permite obtener información más precisa sobre el nivel de logro de un comportamiento o actitud, indicando su presencia o ausencia (Tamayo y Tamayo, 1998). La lista de cotejo quedó estructura en 20 ítems que permitió reportar la presencia o ausencia de los componentes de una estrategia instruccional.

\section{Procedimiento}

En esta investigación se siguieron tres fases:

Fase I. Diseño y validación de los instrumentos. Una vez operacionalizada la variable del presente estudio, se procedió a diseñar el cuestionario de preguntas cerradas y la lista de cotejo que serían empleados en el diagnóstico de este estudio. Ambos instrumentos fueron validados por tres docentes del Instituto Pedagógico de Miranda José Manuel Siso Martínez expertos en el área de estrategias instruccionales y tres docentes de la Universidad Nacional Experimental de la Seguridad (UNES), expertos en el nuevo modelo policial, quienes lo evaluaron y determinaron su validez.

Posterior a su aprobación se le presentó el cuestionario a tres docentes de la Academia de la Policía Municipal de Chacao, quienes administran la unidad curricular Habilidades de comunicación oral y escrita en la formación de funcionarios de la Policía Municipal de Chacao acreditada por la U.N.E.S para dictar el curso de Oficiales de Seguridad Ciudadana a fin de determinar mediante prueba piloto arrojando una confiabilidad de 0.85 de acuerdo con la prueba 20 de Kuder Richardson.

\section{Fase II Aplicación de los instrumentos.} Los instrumentos se aplicaron a los seis docentes que administran la unidad curricular "Habilidades de comunicación oral y escrita" en la academia de la Policía Municipal de Sucre. Primero se aplicó el cuestionario, luego el investigador asistió a una clase de cada docente para observar las estrategias que aplicaban durante el desarrollo de las actividades de enseñanza.

Fase III Tabulación de los datos obtenidos. Una vez aplicado el instrumento se tabularon los datos obtenidos en el diagnóstico.

\section{RESULTADOS}

Luego de aplicados los instrumentos denominados: (a) cuestionario, el cual fue respondido por los docentes, y estuvo referido a la administración del curso "Habilidades de comunicación oral y escrita" y (b) lista de cotejo, la cual fue empleada durante la observación directa durante el desarrollo de las clases del curso "Habilidades de comunicación oral y escrita", se detallan los resultados por cada indicador, tanto del cuestionario como de la lista de cotejo, y se presentan las figuras de ambos instrumentos, a manera de comparación.

\section{Indicador: Activación de la atención}

Para el primer indicador referido a si activan la atención de los estudiantes al 
momento de iniciar la clase, cinco de los docentes respondieron que siempre lo hacen y uno que casi siempre activa la atención, es decir, los sujetos respondieron que siempre o casi siempre realizan esta acción; sin embargo, el investigador observó que solo dos de ellos activan dicha atención (ver Figura 1).

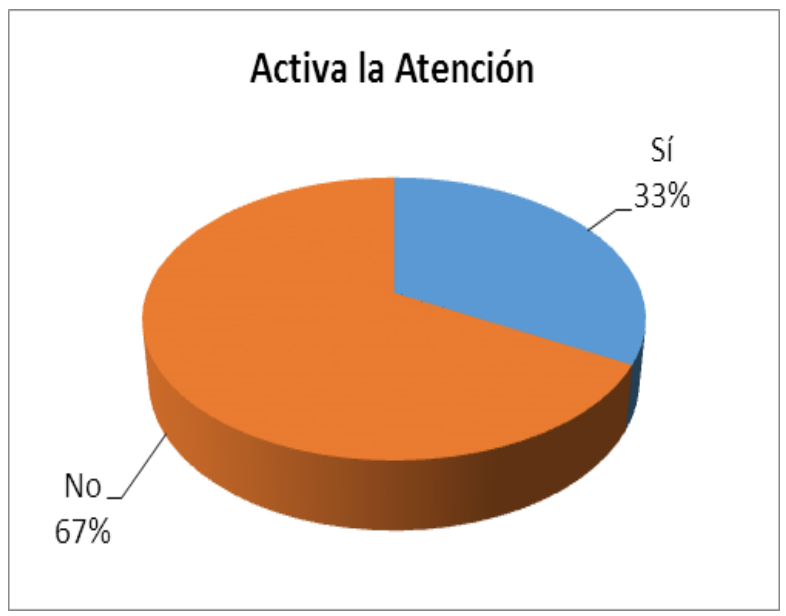

Figura 1. Activa la atención de los estudiantes. (Fuente: Elaborado por el autor)

Indicador: Informa el objetivo de la instrucción

Para este segundo indicador referido a si informan a los estudiantes el objetivo de instrucción a desarrollar en la jornada diaria, se evidenció que todos respondieron que sí lo hacen, mientras que en la observación se reportó que dos de ellos inician las actividades

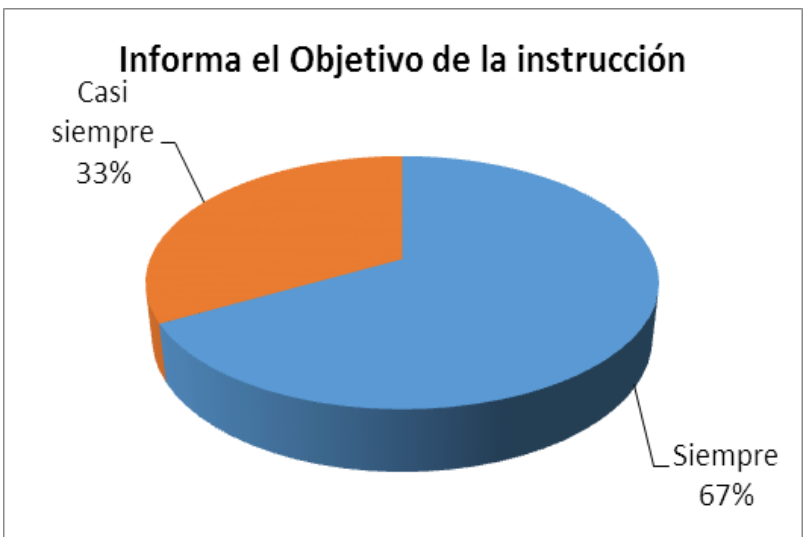

directamente sin hacer mención al propósito de cada lección (ver Figura 2).

Szczurek (1989) plantea que los objetivos de la instrucción orientan globalmente el proceso, indicando lo que se espera lograr. Generalmente esos logros se expresan en términos de lo que el estudiante aprenderá como consecuencia de la instrucción.

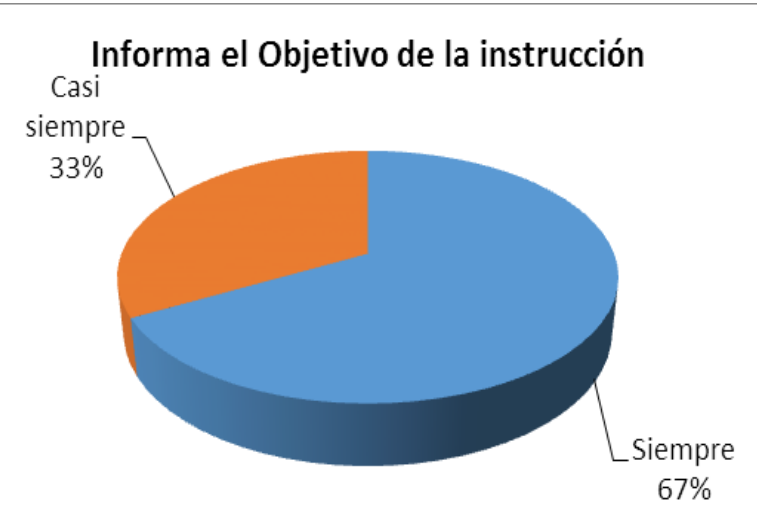

Figura 2. Informa el Objetivo de la Instrucción. (Fuente: Elaborado por el autor) 


\section{Indicador: Aplica un diagnóstico}

Para este tercer indicador se refleja la falta de correspondencia entre lo que dicen los sujetos encuestados y lo que realmente ejecutan en sus aulas de clases: dicen aplicar un diagnóstico para cada clase y la realidad observada demostró que no lo ejecutan (ver Figura 3).

Smith y Ragan (1999) proponen que en toda estrategia instruccional, se debe hacer un esfuerzo para que el educando valore los nuevos contenidos como relevantes $y$ significativos para su vida; en este punto es importante haber realizado el diagnóstico inicial a los estudiantes ya que con dicha información es posible conectar los contenidos a impartirse con los intereses y aspiraciones de los aprendices.
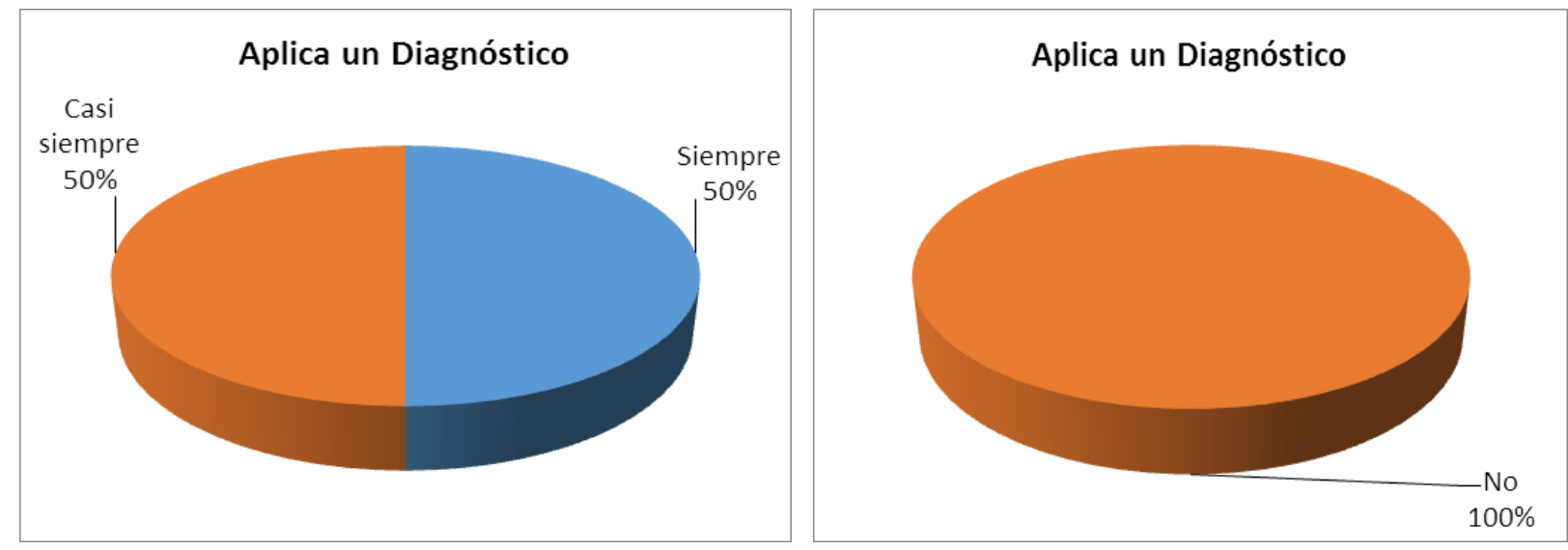

Figura 3. Aplica un diagnóstico. (Fuente: Elaborado por el autor)

\section{Indicador: Activa los conocimientos previos}

En este cuarto indicador, se observa que los docentes encuestados nuevamente respondieron que ejecutan la acción solicitada - activar conocimientos previos en sus estudiantes- pero en la observación de sus clases no lo demostraron, a excepción del docente 2 quien sí los activó (ver Figura 4).
Estos docentes manifestaron que desconocen la importancia de conocer previamente las realidades del grupo de estudiantes donde será impartida la instrucción, relacionando sus características sociales, creencias, valores y conocimientos previos, con el fin de ser tomados en cuenta al momento de efectuar el proceso de enseñanza y de aprendizaje. 

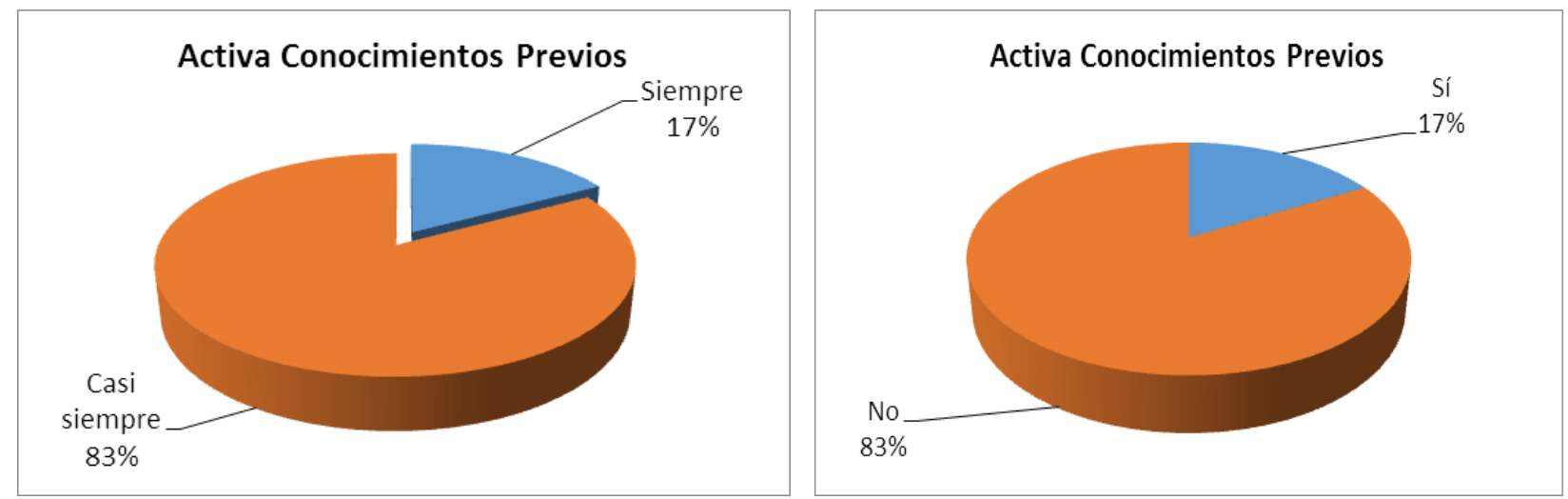

Figura 4. Activa conocimientos previos. (Fuente: Elaborado por el autor)

\section{Indicador: Presenta los nuevos contenidos}

En este quinto indicador se desprende que los docentes presentan explícitamente los nuevos contenidos a aprender, quizás es lo mejor que hacen pues fueron formados para enseñar a otros. Sin embargo, muchas veces no incluye en este proceso todos los componentes propios de una instrucción. Todos los docentes respondieron que siempre presentan el contenido; sin embargo, el investigador en uno de ellos observó que no presenta la información nueva a aprender (ver Figura 5).
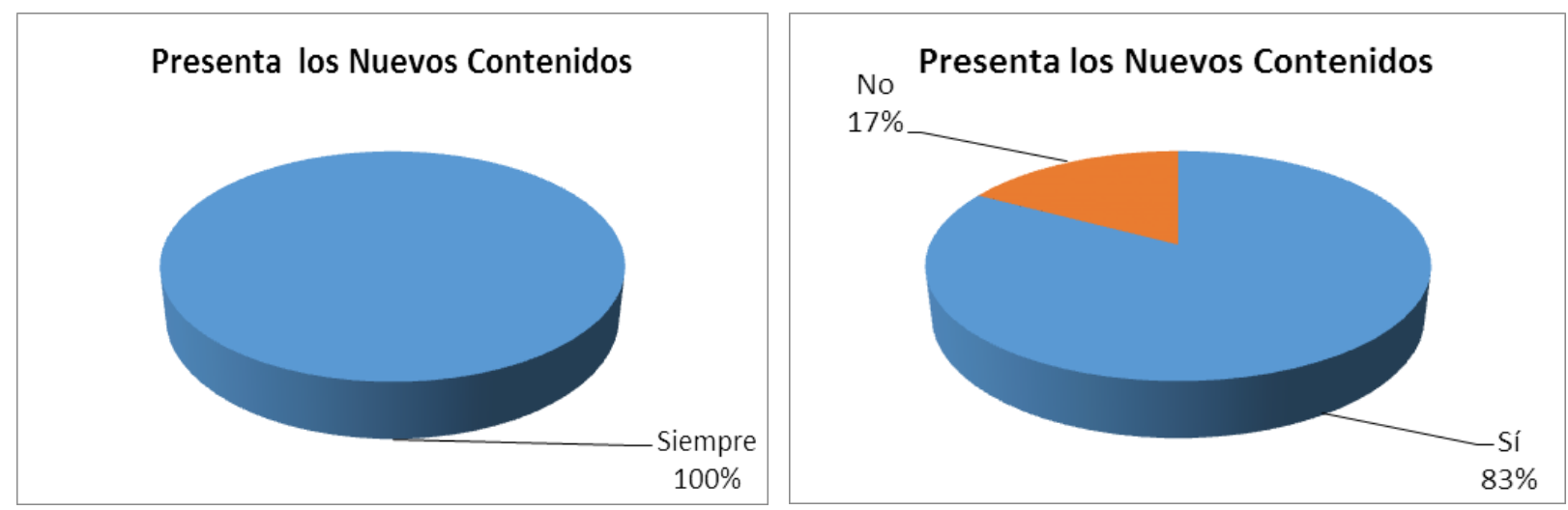

Figura 5. Presenta los nuevos contenidos. (Fuente: Elaborado por el autor)

\section{Indicador: Presenta ejemplos}

En este sexto indicador son evidentes las coincidencias en ambos instrumentos en cuanto a que si presentan ejemplos en todas las clases. Se tiene entonces que los docentes respondieron con una alta frecuencia el uso de ejemplos en sus clases y esto fue confirmado durante las observaciones realizadas por el investigador. (ver Figura 6) 

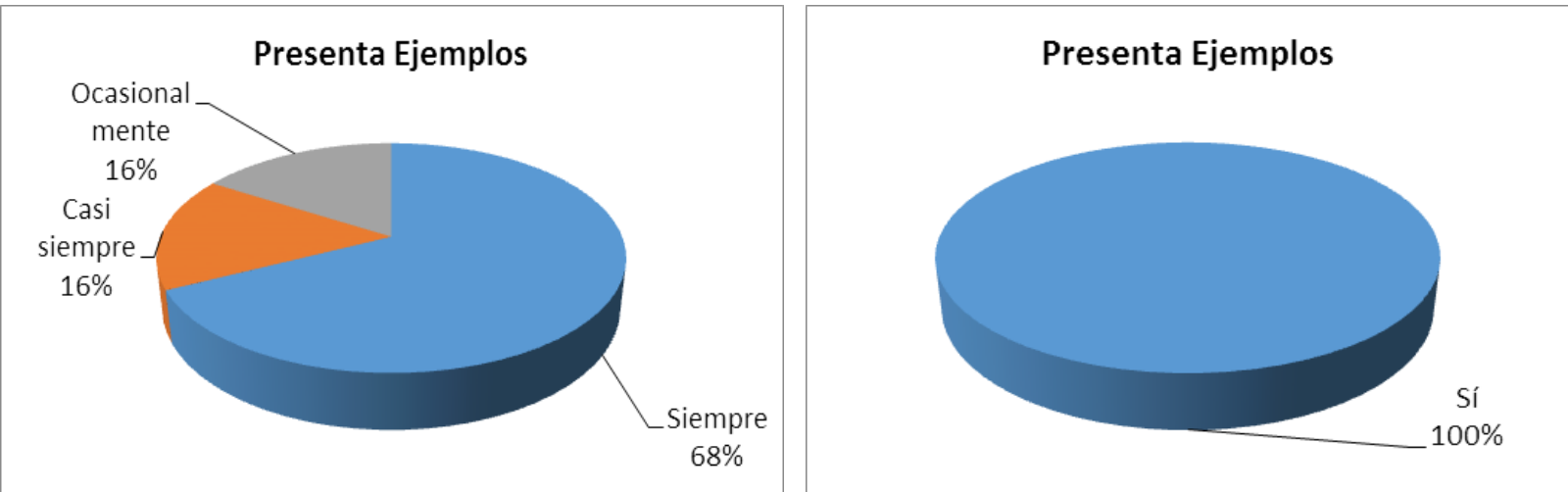

Figura 6. Presenta ejemplos. (Fuente: Elaborado por el autor)

\section{Indicador: Incentiva actividades individuales}

En el séptimo indicador, el cual se refiere a si el docente incentiva las actividades individuales en el estudiante con el fin de que aprenda o consolide el contenido; en el cuestionario todos respondieron que sí las aplicaban pero en la lista de cotejo el investigador reportó que ninguno lo hacía (ver Figura 7). Por tanto, se aclara que estos sujetos no demostraron en la práctica lo que decían que manejaban.

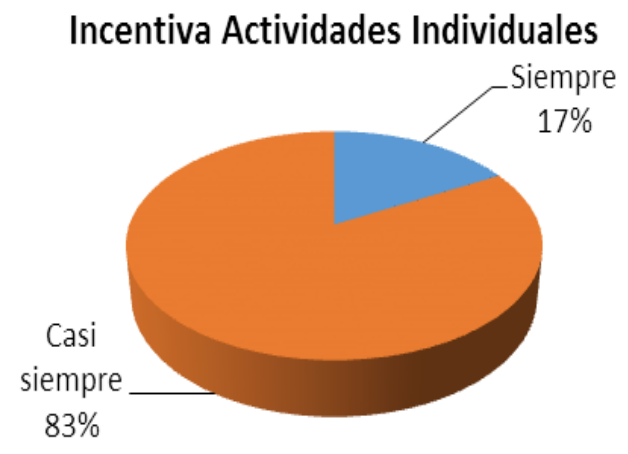

\section{Incentiva Actividades Individuales}

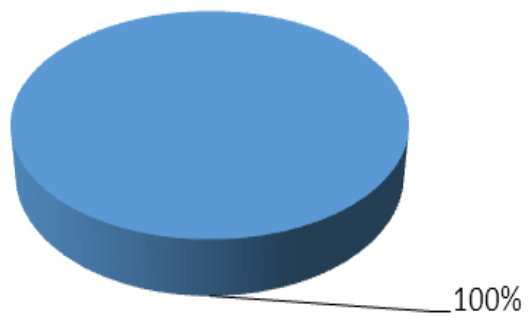

Figura 7. Incentiva actividades individuales. (Fuente: Elaborado por el autor)

\section{Indicador: Introduce prácticas del contenido}

En el octavo indicador se evidencia que los docentes manifestaron que sí introducen prácticas del contenido pero en el desarrollo de su clases no se observó práctica alguna y esto ocurrió con todos los docentes, una ausencia total de la práctica que reforzara el aprendizaje (ver Figura 8). Como estrategia de desarrollo es fundamental incluirla.

Alfonzo (2003) explica que el evento de "Practicar" debe tomarse en cuenta en el momento instruccional del desarrollo y se refiere a dar la posibilidad a los estudiantes de aplicar el conocimiento impartido a fin de que sea afianzado y manejado efectivamente. Las 
prácticas deben estar relacionadas con el tipo de contenido que se esté aprendiendo, sean estos conceptuales, en los cuales se puede implementar como práctica la ejemplificación o en procedimentales o actitudinales en los cuales la práctica resulta casi imprescindible para el aprendizaje e internalización de estos contenidos.
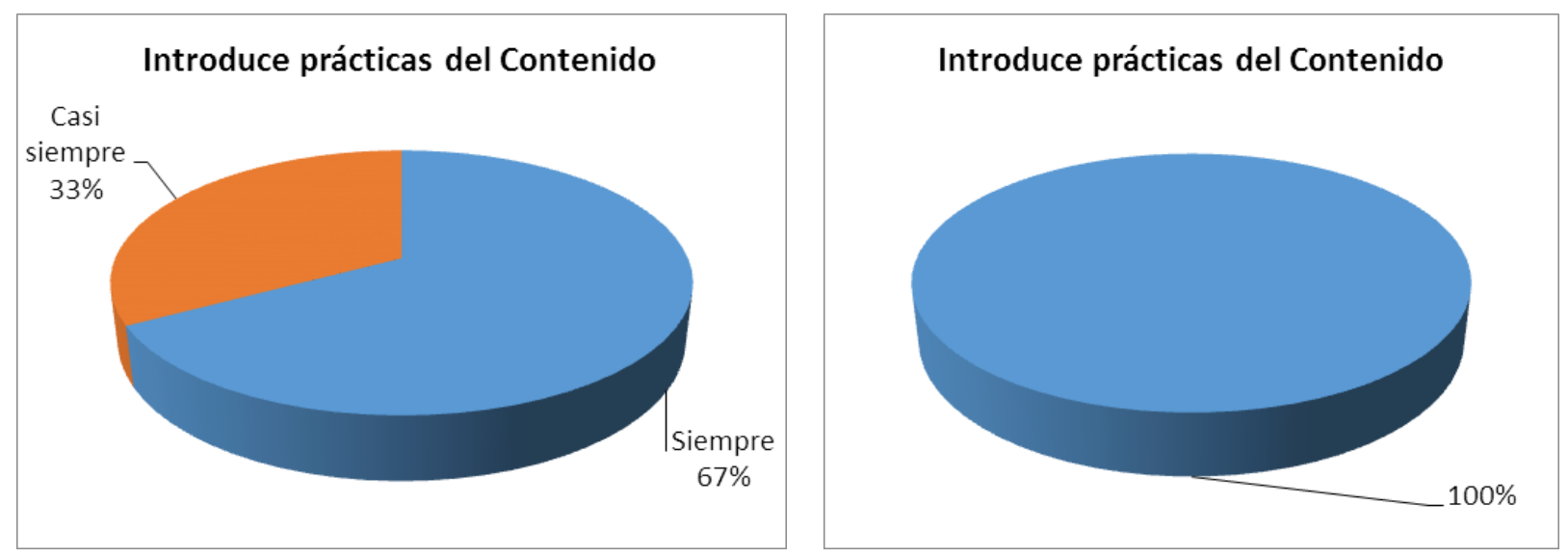

Figura 8. Introduce prácticas del contenido. (Fuente: Elaborado por el autor)

\section{Indicador: Aclara dudas}

En el noveno indicador, los docentes demostraron que siempre están prestos a aclarar las dudas de los estudiantes. Así se evidenció tanto en la encuesta como en el desarrollo de las clases (ver Figura 9). 

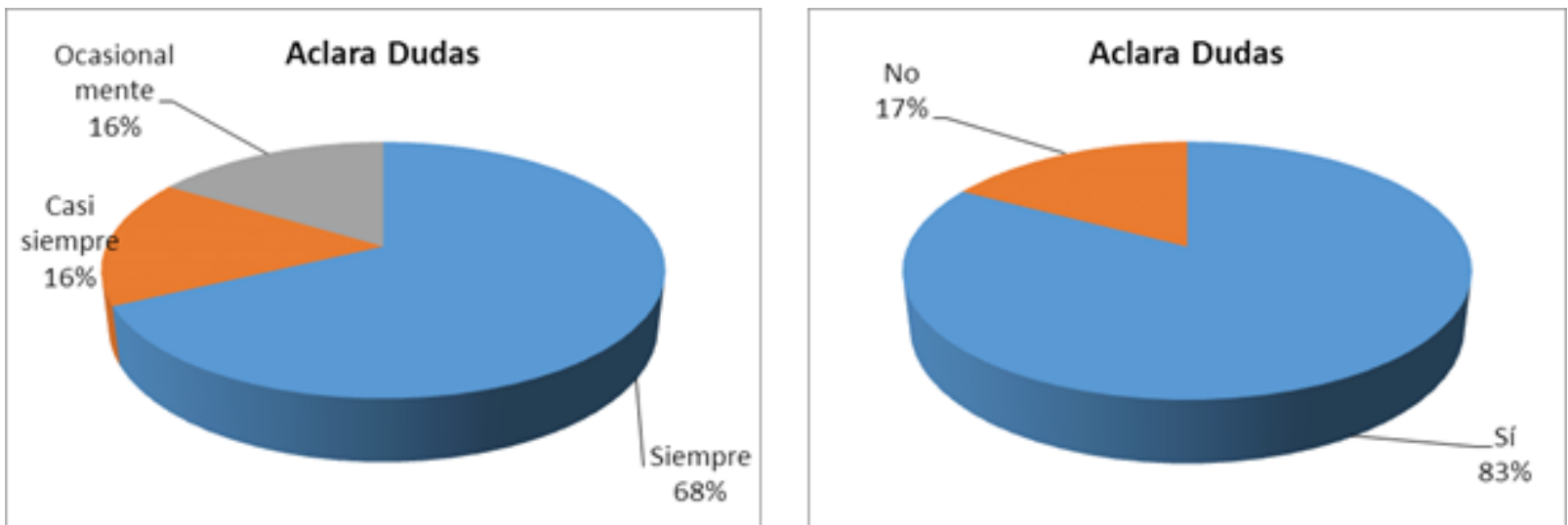

Figura 9. Aclara duda. (Fuente: Elaborado por el autor)

Indicador: Promueve la elaboración de resumen

En el décimo indicador se observa que los docentes manifestaron que siempre, casi siempre $\mathrm{u}$ ocasionalmente promueven el resumen en sus estudiantes; pero en las clases observadas no se evidenció esta práctica. (Ver Figura 10)

Al revisar y resumir la lección se busca garantizar que los estudiantes hayan incorporado la nueva información además de mejorar la capacidad de sintetizar lo aprendido por parte de los aprendices. En este evento se presenta la oportunidad de que el docente aclare algún contenido que no haya sido bien comprendido y se profundice en la comprensión de lo aprendido (Alonzo, 2003).

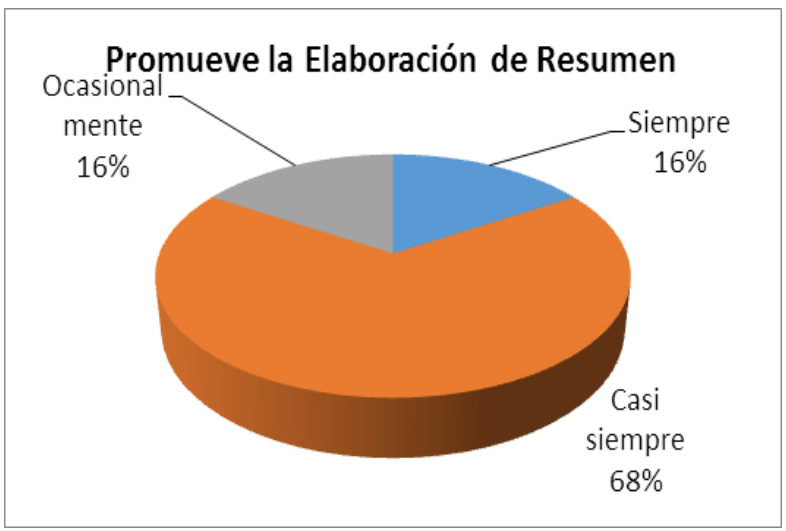

\section{Promueve la Elaboración de Resumen}

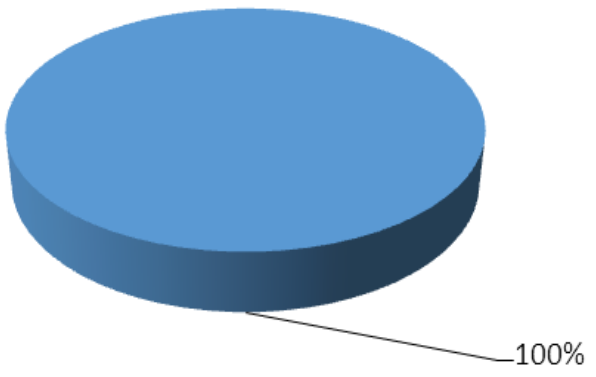

Figura 10. Promueve la elaboración de resumen. (Fuente: Elaborado por el autor) 
Indicador: Promueve la transferencia de aprendizajes

En el décimo primer indicador se puede notar tanto en la encuesta como en la observación a las clases que los docentes sí promueven la transferencia de los aprendizajes, especialmente en el curso Habilidades de comunicación oral y escrita, cuyos contenidos a aprender deben ser aplicados tanto en otros cursos como en el campo laboral de un funcionario policial (ver Figura 11). Esto lo tienen claros estos docentes $y$, por ello, hacen de la transferencia una práctica.
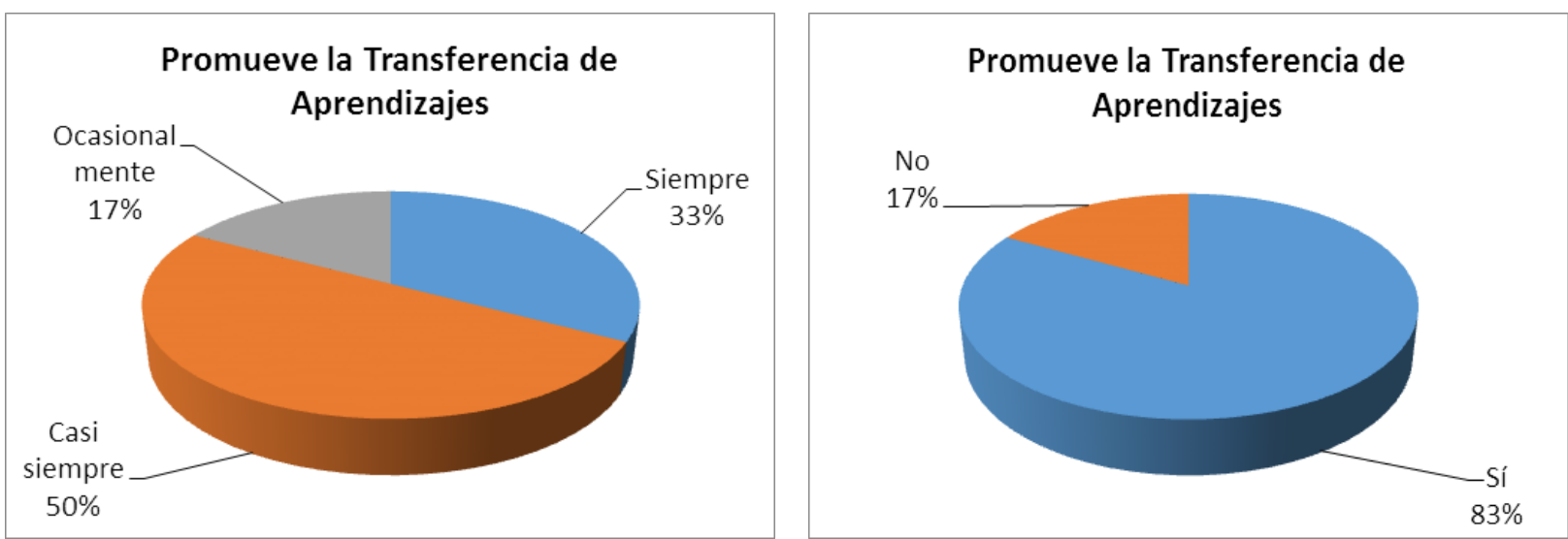

Figura 11. Promueve la transferencia de aprendizajes. (Fuente: Elaborado por el autor)

\section{Indicador: Resalta la utilidad de lo aprendido}

En el décimo segundo indicador es una muestra de que los docentes están claros en que los estudiantes deben aprender la importancia y la utilidad de los contenidos programáticos, pues tanto en la encuesta como en la lista de cotejo hay coincidencias en este aspecto (ver Figura 12).
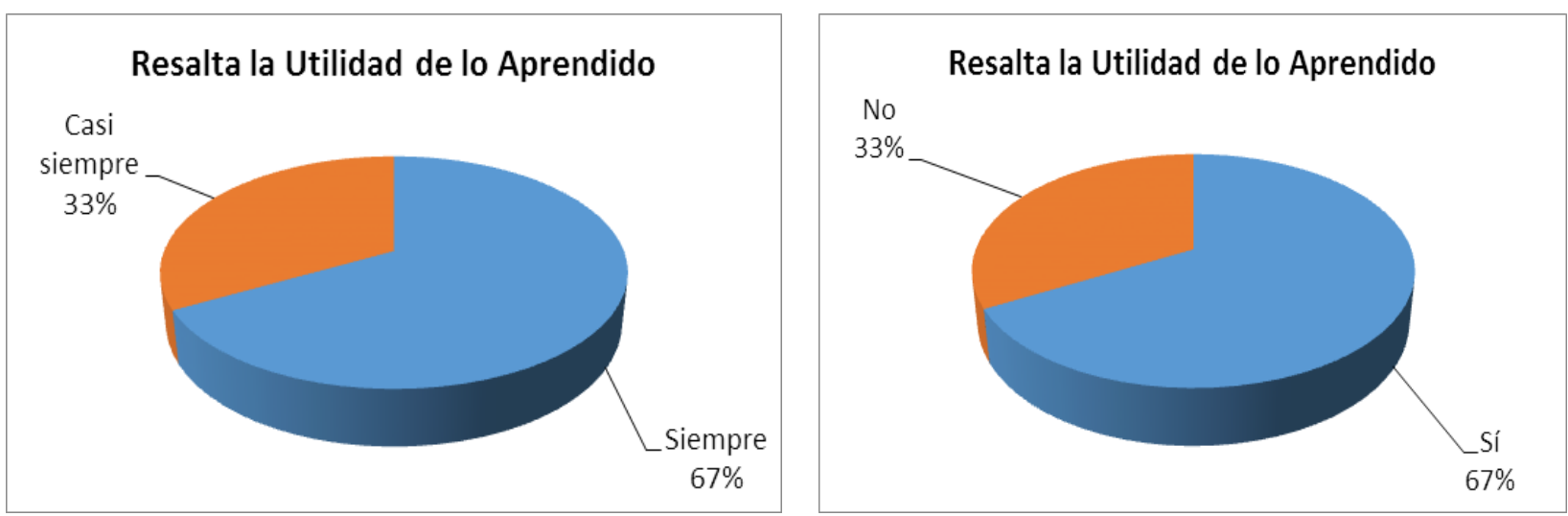

Figura 12. Resalta la utilidad de lo aprendido. (Fuente: Elaborado por el autor) 
Indicador: Emplea medios y recursos

\section{instruccionales}

En el décimo tercer indicador, se evidencia que la mayoría de estos docentes hacen uso de medios y recursos para apoyar los procesos de enseñanza y aprendizaje (ver Figura 13). Szczurek (1989) manifiesta que un medio es cualquier persona, organismo u objeto que proporciona la información necesaria para facilitar un determinado aprendizaje de conocimientos, actitudes $\mathrm{O}$ habilidades. Esto refiere a que los medios contienen la información en sí mismos, por lo que probablemente se requiere de recursos adicionales para que se efectúe la transmisión de la información.

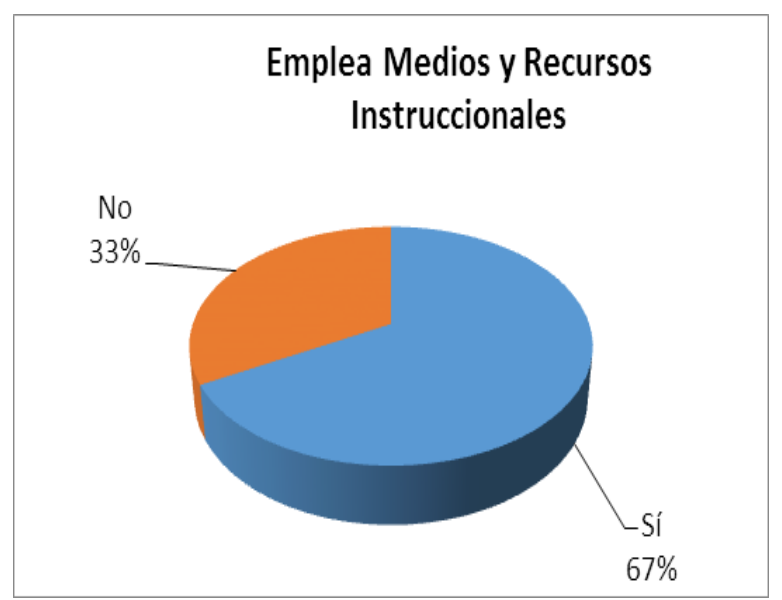

Figura 13. Emplea medios y recursos instruccionales. (Fuente: Elaborado por el autor)

\section{Indicador: Valora la actuación del estudiante}

En el décimo cuarto indicador, se muestra una total divergencia pues en la encuesta todos los docentes afirmaron que valoran la actuación del estudiante tanto formativa como sumativamente; mientras que en la observación el resultado fue opuesto porque no hubo evidencia de valoración alguna (ver Figura 14).
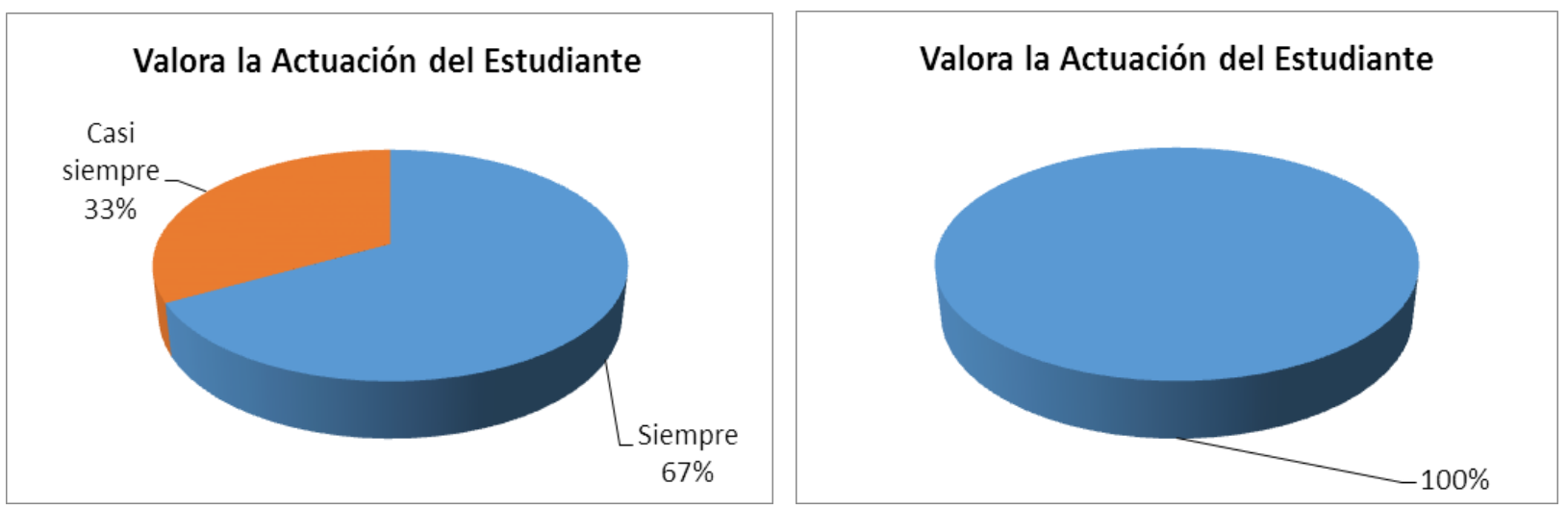

Figura 14. Valora la actuación del estudiante. (Fuente: Elaborado por el autor) 


\section{Indicador: Evalúa el proceso} instruccional

En el décimo quinto indicador también se muestra una total divergencia pues en la encuesta todos los docentes afirmaron que evaluaban todo el proceso instruccional; mientras que en la observación el resultado fue opuesto porque no hubo evidencia de evaluación de este proceso en su totalidad (ver Figura 15). Szczurek (1989) plantea que tanto la evaluación cualitativa como la cuantitativa proporcionan la información necesaria para identificar la efectividad, la eficiencia, el valor y los méritos del proceso instruccional, con el fin de controlar y tomar decisiones relacionadas al proceso. Debe valorarse tanto formativa como sumativamente.

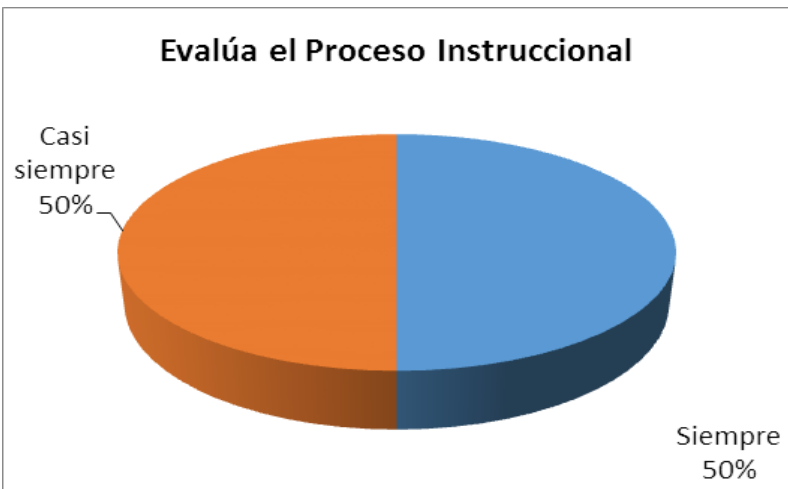

\section{Evalúa el Proceso Instruccional}

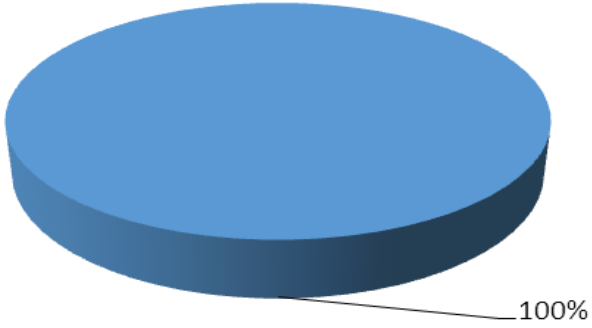

Figura 15. Evalúa el proceso instruccional. (Fuente: Elaborado por el autor)

\section{Indicador: Incluye plan de actividades}

En el décimo sexto indicador se reporta que en la encuesta los docentes respondieron que sí incluyen un plan de actividades pero en la observación ese plan estuvo ausente a excepción de un solo informante quien sí mostró unas actividades previamente organizadas por ella, pero en su mayoría los docentes no incluyen un plan (ver Figura 16).
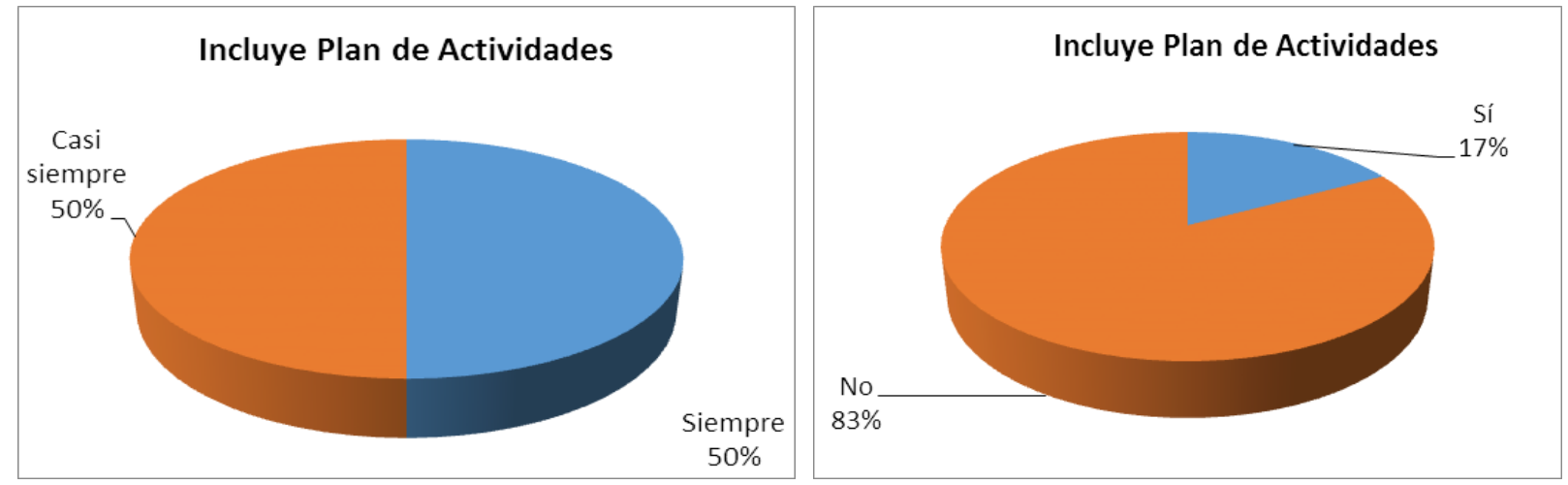

Figura 16. Incluye plan de actividades. (Fuente: Elaborado por el autor) 


\section{Indicador: Organiza espacio y mobiliario}

En el décimo séptimo indicador, los docentes manifestaron que sí toman en cuenta la organización del espacio de clases y el mobiliario a utilizar pero en la observación fueron totalmente obviados por ellos (ver Figura 17). Para Szczurek (1989), "el docente debería intervenir deliberadamente en la regulación del ambiente y no conformarse con prestar atención solamente al estudiante como si este estuviera aislado del ambiente que lo rodea" (p. 20). En este sentido, los docentes deben tomar en cuenta los elementos físicos tales como el espacio, el mobiliario, el clima, la humedad, la ventilación, la iluminación, promoviendo los cambios pertinentes, tomando en cuenta las distancias y ángulos de visión, el ruido y dirección del sonido en el ambiente de enseñanza, originando una mejor distribución de las sillas, mesas y otros elementos en beneficio del hecho educativo.

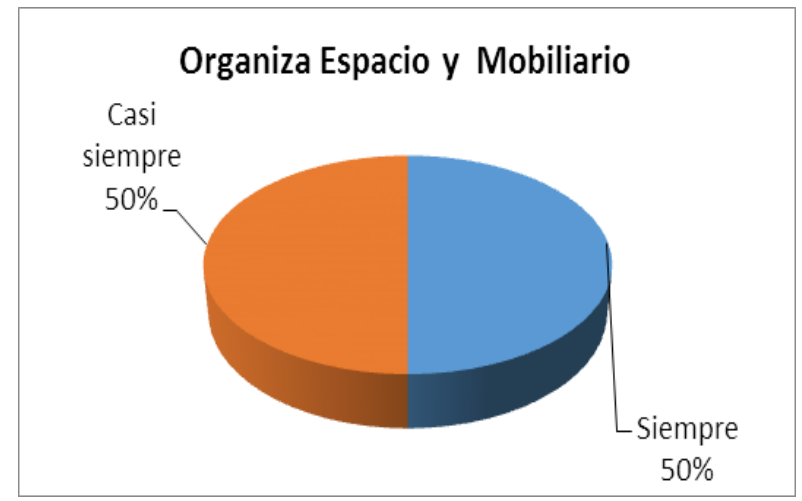

Organiza Espacio y Mobiliario

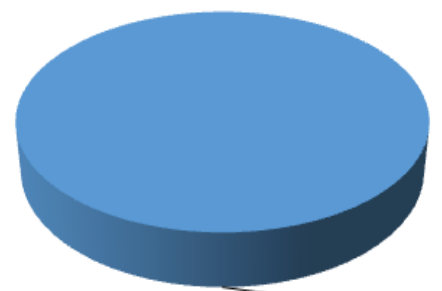

Figura 17. Organiza espacio y mobiliario. (Fuente: Elaborado por el autor)

CONCLUSIONES

La estrategia instruccional debe ser conscientemente elaborada por el docente con la finalidad de promover el aprendizaje en los estudiantes; además se deben considerar todos sus elementos, los cuales contribuyen al logro de los objetivos previamente propuestos en el proceso instruccional y además deben considerarse los momentos instruccionales de inicio, desarrollo y cierre que permitan al estudiante percibir selectivamente la nueva información y apropiarse de ella.

De allí que al diagnosticar las estrategias instruccionales que emplean los docentes que administran la unidad curricular Habilidades de comunicación oral y escrita en la Academia de la Policía Municipal de Sucre, se concluye que los docentes que laboran en esta institución omiten la planeación, ejecución y evaluación de una estrategia instruccional, por cuanto desconocen la forma cómo se organizan y llevan a cabo las situaciones de enseñanza con el fin de promover determinados aprendizajes. La organización secuencial del contenido a aprender, la selección de los medios instruccionales idóneos para presentar ese contenido y la organización de los estudiantes representaron elementos ausentes durante el proceso investigativo llevado a cabo.

Los docentes, sujetos de esta investigación, comprendieron que para planificar e intervenir pedagógicamente con eficacia es vital el manejo 
adecuado de estrategias instruccionales haciendo uso de todos los recursos que estén al alcance de la institución en beneficio de los procesos de enseñanza y aprendizaje.

\section{REFERENCIAS}

Alfonzo, A. (2003). Estrategias Instruccionales. Recuperado de http://www.medusa.unimet. edu.ve/educacion/fbqi21/estrategias.pdf

Arias, F. (2006). El proyecto de investigación: Introducción a la metodología científica. $5^{a}$ edición. Caracas: Episteme

Comisión Nacional para la Reforma Policial [CONAREPOL]. (2007). Recomendaciones Generales. Caracas: MPPRIJ

Consejo General de Policía- Comisión Nacional para la Reforma Policial (2010). Orden en la Sala. Practiguía sobre la adecuación de la base Jurídica y Estructura Organizativa de los Cuerpos de Policía. Colección Baquía. Reglas mínimas de estandarización para los cuerpos policiales. Caracas

Farci, L. y Ruíz, B. (2007). Proyecto de Investigación en Ciencias. Caracas: Panapo

Guerrero, J. (2018). Estrategias instruccionales para abordar la unidad curricular Habilidades de comunicación oral y escrita del curso básico para oficiales de seguridad ciudadana en la Academia de la Policía Municipal de Sucre (trabajo de maestría). Universidad
Pedagógica Experimental Libertador (UPEL), Instituto Pedagógico de Miranda José Manuel Siso Martínez (IPMJMSM), Caracas, Venezuela

Ley Orgánica del Servicio de Policía y del Cuerpo de Policía Nacional Bolivariana. (2008). Gaceta Oficial de la República Bolivariana de Venezuela, 39.303, Noviembre 10

Márquez, O. (2006). El Proceso de la Investigación en las Ciencias Sociales. Barinas, Venezuela: Ediciones UNELLEZ

Monje, C. (2011). Metodología de la investigación cualitativa y cuantitativa. [Libro en Línea]. Universidad Surcolombiana. Facultad de Ciencias Sociales y Humanas. Recuperado de https://carmonje.wikispaces.com/file/view /Monje+Carlos+Arturo++Gu\%C3\%ADa+did\%C3\%A1ctica+Metod olog\%C3\%ADa+de+la+investigaci\%C3\% B3n.pdf

Smith, P. y Ragan, T. (1999). Instruccional design. New Jersey: Merrill Prentice Hall

Szczurek, M. (1989). La estrategia instruccional. En Revista Investigación y Postgrado. 4 (2), 7-25

Tamayo, M. (2004). El proceso de la

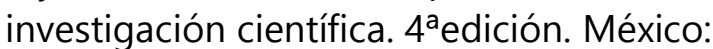
Limusa

Tamayo, G. y Tamayo, M. (1998). Proceso de investigación científica. México: Limusa 